\title{
Restrained eating in Lebanese adolescents: scale validation and correlates
}

Tracy Boulos Nakhoul', Anthony Mina', Michel Soufia ${ }^{1 \dagger}$, Sahar Obeid ${ }^{2,3,4^{*}+}$ and Souheil Hallit ${ }^{1,2^{*}+}$

\begin{abstract}
Background: Restrained eating disorder is prevalent worldwide across both ethnic and different cultural groups, and most importantly within the adolescent population. Additionally, comorbidities of restrained eating present a large burden on both physical and mental health of individuals. Moreover, literature is relatively scarce in Arab countries regarding eating disorders, let alone restrained eating, and among adolescent populations; hence, the aim of this study was to (1) validate the Dutch Restrained Eating Scale in a sample of Lebanese adolescents and (2) assess factors correlated with restrained eating (RE), while taking body dissatisfaction as a moderator between body mass index (BMI) and RE.

Methods: This cross-sectional study, conducted between May and June 2020 during the lockdown period imposed by the Lebanese government, included 555 adolescents aged between 15 and 18 years from all Lebanese governorates (mean age of $16.66 \pm 1.00$ years). The scales used were: Dutch Restrained Eating Scale, body dissatisfaction subscale of the Eating Disorder Inventory-Second version, Rosenberg Self-Esteem Scale, Beirut Distress Scale (for psychological distress), Hamilton Anxiety Rating Scale and Patient Health Questionnaire (for depression).

Results: The Confirmatory factor analysis results were obtained as follows: $X 2 / \mathrm{df}=159.88 / 35=4.57, C F I=0.96, T L I=0.95$, RMSEA $=0.08$ [0.068-0.093]. Female gender $(B=0.19)$, higher $B M I(B=0.49)$, higher physical activity index $(B=0.17)$, following a diet to lose weight $(B=0.26)$, starving oneself to lose weight $(B=0.13)$, more body dissatisfaction $(B=1.09)$, higher stress $(B=0.18)$ were significantly associated with more restrained eating, whereas taking medications to lose weight $(B=-0.10)$ was significantly associated with less restrained eating. The interaction BMI by body dissatisfaction was significantly associated with restrained eating; in the group with low BMl, high body dissatisfaction was significantly associated with more restrained eating. The factor analysis yielded a one-factor solution with Eigen values $>1$ (variance explained $=59.65 \%$; $\left.a_{\text {cronbach }}=0.924\right)$. Female gender $(B=0.19)$, higher $B M I(B=0.49)$, higher physical activity index $(B=0.17)$, following a diet to lose weight $(B=0.26)$, starving oneself to lose weight $(B=0.13)$, more body dissatisfaction $(B=1.09)$, and higher stress $(B=0.18)$ were significantly associated with more $R E$, whereas taking medications to lose weight $(B=-0.10)$ was significantly associated with less RE. The interaction body mass index (BMI) by body dissatisfaction was significantly associated with RE; in the group with low BMI, higher body dissatisfaction was significantly associated with more RE.
\end{abstract}

\footnotetext{
* Correspondence: saharobeid23@hotmail.com; souheilhallit@hotmail.com

${ }^{+}$Michel Soufia, Sahar Obeid and Souheil Hallit are last co-authors.

${ }^{2}$ INSPECT-LB: National Institute of Public Health, Clinical Epidemiology and Toxicology, Beirut, Lebanon

${ }^{1}$ Faculty of Medicine and Medical Sciences, Holy Spirit University of Kaslik (USEK), Jounieh, Lebanon

Full list of author information is available at the end of the article
}

(c) The Author(s). 2021 Open Access This article is licensed under a Creative Commons Attribution 4.0 International License, which permits use, sharing, adaptation, distribution and reproduction in any medium or format, as long as you give appropriate credit to the original author(s) and the source, provide a link to the Creative Commons licence, and indicate if changes were made. The images or other third party material in this article are included in the article's Creative Commons licence, unless indicated otherwise in a credit line to the material. If material is not included in the article's Creative Commons licence and your intended use is not permitted by statutory regulation or exceeds the permitted use, you will need to obtain permission directly from the copyright holder. To view a copy of this licence, visit http://creativecommons.org/licenses/by/4.0/ The Creative Commons Public Domain Dedication waiver (http://creativecommons.org/publicdomain/zero/1.0/) applies to the data made available in this article, unless otherwise stated in a credit line to the data. 
Conclusions: Our study showed that the Dutch Restrained Eating scale is an adapted and validated tool to be used among Lebanese adolescents and revealed factors associated with restrained eating in this population. Since restrained eating has been associated with many clinically-diagnosed eating disorders, the results of this study might serve as a first step towards the development of prevention strategies targeted towards promoting a healthy lifestyle in Lebanese adolescents.

Keywords: Restrained eating, Body dissatisfaction, Body mass index, Adolescents, Lebanon, Dutch Restrained Eating Scale, Body dissatisfaction subscale of the Eating Disorder Inventory-Second version (EDI-2), Beirut Distress Scale, Validation

\section{Background}

The term "Eating disorders" represents multiple serious conditions characterized by disordered eating behaviors negatively impacting the physical and mental health of a person, as well as his/her ability to properly function [1]. Eating disorders rank third in terms of chronic diseases [2], are increasing in adolescents [3], are more present in Western compared to Asian countries [4], and are more frequent in females than in males [4].

Among eating disorders, restrained eating (RE) is defined as a behavior "to restrict food intake deliberately in order to prevent weight gain or promote weight loss" [5]. However, some studies indicated that episodes of restrained eating were followed by time intervals of disinhibition towards eating and consequently, weight gain [6, 7]. Moreover, other studies indicated the possibility of stress triggering this alternating restrained/disinhibited eating episode $[8,9]$; and hence forming a vulnerable weight cycle [9]. Hormonal changes, along with physical changes and behavioral changes in adolescents, are important factors that might influence the development of restrained eating in these individuals, thus, making it a frequent eating disorder reported in adolescents [10]. Actually, multiple other factors (demographic, social, psychological, etc.) were shown to be associated with restrained eating as well.

\section{Sociodemographic factors}

Females are generally influenced by their body image more than males [11], with adolescent females being less happy about their bodies than adolescent males (20). When comparing boys and girls with the same body mass index (BMI), boys showed more satisfaction of their bodies, while girls were more likely to attempt weight loss maneuvers [11].

\section{Physical activity}

A correlation seems to exist between physical activity and restrained eating. The results of a previous study indicated that girls at high risk of developing an eating disorder, performed more physical activity, with the goal of losing weight [12]. Indeed, more eating restriction was observed in adolescents who practiced more physical activity [12].

\section{Social factors}

Social factors include family, parents and media. A previous study demonstrated that teasing by family and friends, as well as internalized weight stigma, especially that related to weight and body shame and guilt, are correlated with eating disorder [12]. Parents, family and media can lead the individual to restrained eating by influencing him/her to reach the "perfect weight" [13, 14]. An illustrative example is that excessive watching of reality and entertainment shows leads to disordered eating in women [15]. Media perfectionism, and media pressure increase the occurrence of body dissatisfaction that can lead to restrained eating [16]. Even though parents are a source of social support, they can increase teens' body dissatisfaction by criticizing their appearance, hence, contributing to the development of restrained eating [17].

\section{Psychological factors}

Among those factors emerges body dissatisfaction. Its core "negative feeling about the body" affects restrained eating both directly and indirectly by different pathways $[8,18,19]$. Having thinner body ideals as a tool for better social recognition among peers, is a well-established concept among adolescents, paving way for more body dissatisfaction and increased effort to lose weight among them [20]. Furthermore, adolescents with a high BMI level are more likely to get dissatisfied with their current weight, and become prone to weight decreasing maneuvers, particularly restrained eating [18].

Another psychological factor is depression. There is a positive correlation between depression and restrained eating in women, but not men [18]. In women, the positive effect of depression on restrained eating suggests that focusing on food, eating or dieting may be a broader group of methods for escaping awareness of negative emotions [17]. In men, depression inhibits, rather than facilitates, restrained eating, suggesting that men do not use food to regulate their emotions, and do not rely on diet to escape unwanted emotions $[17,18]$. 
Thus, based on previous studies [11, 18, 21, 22], body dissatisfaction seems to play a moderating role between multiple factors (body mass index, physical activity, depression, self-esteem, gender) and restrained eating. Based on the before mentioned studies, the following trans-theoretical model of restrained eating was developed (Fig. 1).

Multiple scales are used for the assessment of restrained eating: Dutch Eating Behavior Questionnaire, Eating Inventory (EI), Revised Restraint Scale (RS), and the Current Dieting Questionnaire [23]. The Dutch Eating Behavior Questionnaire (DEBQ), originally developed by Van Strien et al. in 1986, assesses restrained, emotional, and external eating behavior [24]. In addition, subsequent exploratory and confirmatory factor analyses generally have supported the original three-factor structure [25]. The DEBQ has equivalent psychometric properties and factor structure in men and women and across the full range of weight categories. In this study, only the restrained questionnaire will be adopted. The Dutch Restrained Eating Scale (DRES) was validated in different languages in adolescents' populations, mainly French [26], Maltese [27] and Spanish [28], with the last two studies validating the DRES in female gender exclusively $[27,28]$. A study conducted in Lebanon about restrained eating did validate the Arabic version of the Dutch Restrained Eating Scale in adults [29].

Restrained eating disorder is prevalent worldwide across both ethnic and different cultural groups [30] and most importantly within the adolescent population [31]. Additionally, comorbidities of restrained eating present a large burden on both physical and mental health of individuals [32]. Moreover, literature is relatively scarce in
Arab countries on eating disorder, let alone restrained eating, and in adolescents populations; hence, the aim of this study was to (1) validate the Arabic version of the Dutch Restrained Eating Scale and (2) assess factors associated with restrained eating among a sample of Lebanese adolescents, while taking body dissatisfaction as a moderator between BMI and RE.

\section{Methods}

\section{Study design}

This cross-sectional study, conducted between May and June 2020 during the lockdown period imposed by the Lebanese government, included 555 adolescents aged between 15 and 18 years old from all Lebanese governorates (Beirut, Mount-Lebanon, South, North, Bekaa). Our sample was chosen using the snowball technique; the research team contacted adolescents in their contact lists from different schools; those students were instructed to forward the link to the questionnaire to their classmates via the WhatsApp application. The first page of the questionnaire included an explanation of the study topic and objective, a statement ensuring the anonymity of respondents and an explanation for the student to get his/ her parents' approval before participation. The student had to select the option stating "I got my parents' approval and I consent to participation in this study" to be directed to the questionnaire.

The mean age of the participants was $16.66 \pm 1.00$ years, with $75.7 \%$ females. More details about the students can be found in Table 1. The mean restrained eating score in the total sample was $26.30 \pm 9.37$ (skewness $=0.203$; kurtosis $=-0.656$ ).

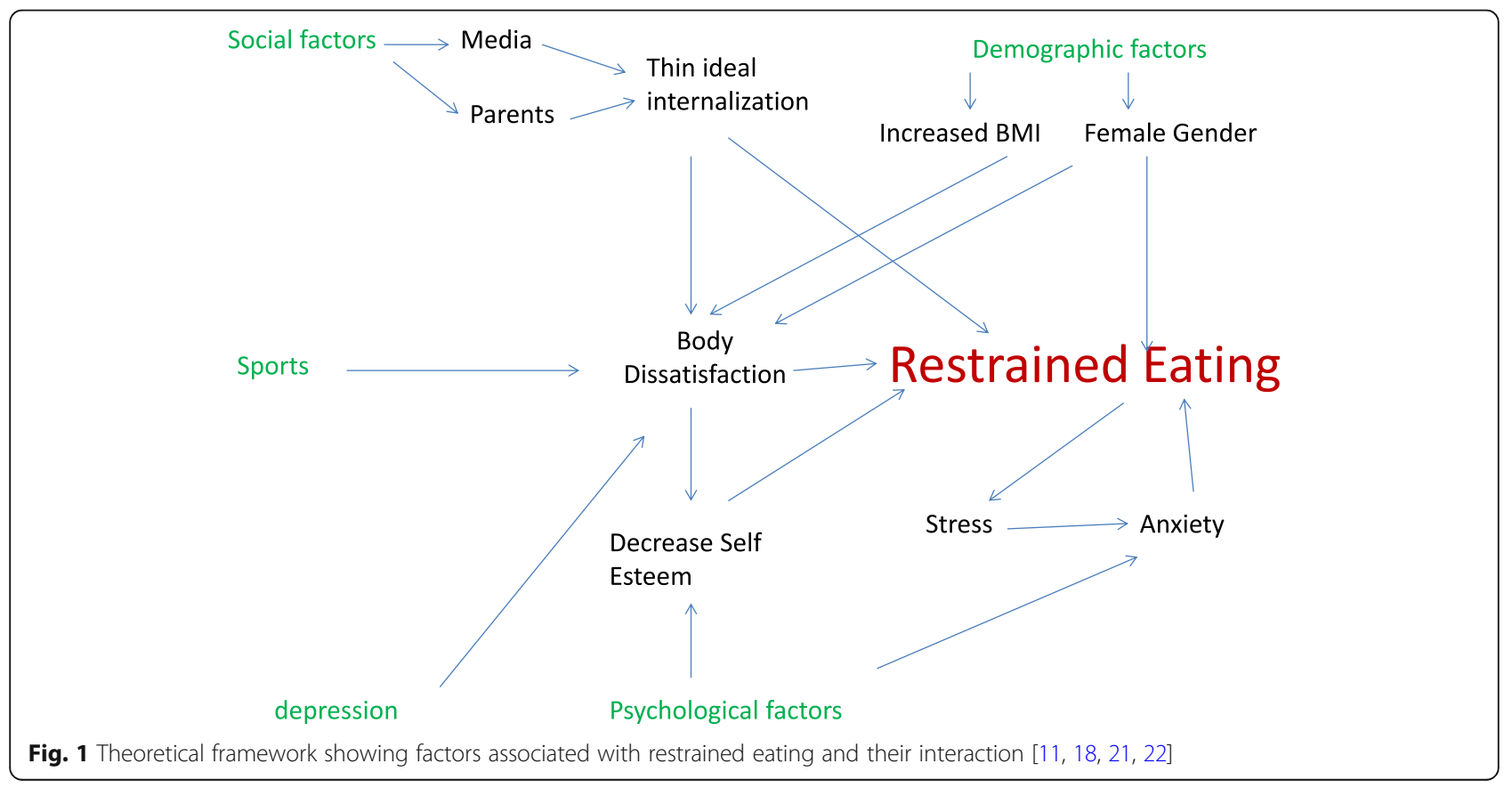


Table 1 Sociodemographic and other characteristics of the participants $(N=555)$

\begin{tabular}{ll}
\hline Variable & N (\%) \\
\hline Gender & $135(24.3 \%)$ \\
Male & $420(75.7 \%)$ \\
Female & \\
District & $62(11.2 \%)$ \\
Beirut & $332(59.8 \%)$ \\
Mount Lebanon & $92(16.6 \%)$ \\
North & $29(5.2 \%)$ \\
South & $40(7.2 \%)$ \\
Bekaa & Mean \pm SD \\
Age (in years) & $16.66 \pm 1.00$ \\
Body Mass Index (kg/m2) & $22.38 \pm 4.00$ \\
House crowding index & $0.99 \pm 0.52$ \\
\hline
\end{tabular}

\section{Minimal sample size}

Since the Dutch Restrained Eating Scale contains 10 items, a sample of 100 adolescents was deemed necessary to conduct a factor analysis (10 participants per 1 scale item according to Comrey and Lee) [33].

\section{Questionnaire}

The first part of the questionnaire contained sociodemographic information about the participants (age, gender, governorate, current weight and height). The household crowding index, reflecting the socioeconomic status of the family [34], is the ratio of the number of persons living in the house over the number of rooms in it (excluding the kitchen and the bathrooms). The physical activity index is the cross result of the intensity, duration, and frequency of daily activity [35].

The second part included the scales used in this study:

\section{Dutch Restrained Eating Scale}

It is composed of 10 questions [36] rated from never (1 point) to always (5 points). Higher scores reflect more restrained eating (Cronbach's $\alpha$ in this study $=0.92$ ).

\section{Body dissatisfaction subscale of the Eating Disorder Inventory-Second version (EDI-2)}

It is composed of nine items, scored from 0 (sometimes/rarely/never) to 3 (always). Higher scores define more body dissatisfaction (Cronbach's $\alpha$ in this study =0.63) [37].

\section{Rosenberg Self-Esteem Scale}

This scale is used to assess self-esteem [38]. It includes ten items measured on 4-point Likert scale ranging from 1 (strongly disagree) to 4 (strongly agree). Higher scores reflected higher self-esteem (Cronbach's $\alpha$ in this study $=0.74)$.

\section{Beirut Distress Scale (BDS-10)}

This scale, developed in Lebanon [39], was used to assess the intensity of distress. It is composed of ten questions. The points range from 0 (never) to 4 (always). A higher score indicates higher perceived distress (Cronbach's $\alpha$ in this study $=0.82$ ).

\section{Hamilton Anxiety Rating Scale (HAM-A)}

It is composed of fourteen items rated on a 5-point Likert scale ranging from 0 (not present) to 4 (very severe) [40]. Higher scores mean more anxiety. This scale is validated in the Lebanese population [41] (Cronbach's $\alpha$ in this study $=0.89$ ).

\section{Patient Health Questionnaire (PHQ-9)}

This nine-item scale was used to assess depression [42] and is validated in Lebanon [43]. Scores range from 0 (not at all) to 3 (nearly every day). Higher scores indicate higher rates of depression (Cronbach's $\alpha$ in this study $=0.84$ ).

The last part of the questionnaire included general questions retrieved from a previous study [44] about methods to lose weight, dieting, food, external pressures to go on a diet, abuse and family history of eating disorder (i.e. "do you always hear a comment about your weight?", "do your relatives comment on your weight?", "do you feel pressured to go on a diet?", "have you felt pressured by the media to change your diet?", "have you followed any diet to lose weight?"). These variables were classified as categorical variables (yes/no type of answer).

\section{Forward and back translation}

One bilingual psychologist whose mother tongue is Arabic, accomplished the forward translation. The backward translation was performed by another psychologist. The original and translated English versions were compared by one healthcare professional (psychiatrist) for discrepancies, which were resolved by consensus [45-51].

\section{Statistical analysis}

The SPSS software version 23 was used to conduct data analysis. A confirmatory factor analysis (CFA) was carried out on the total sample using SPSS AMOS software v24. Several goodness-of-fit indicators were reported: the Relative Chi-square $\left(\chi^{2 / d f}\right)$, the Root Mean Square Error of Approximation (RMSEA), the Tucker Lewis Index (TLI) and the comparative fit index (CFI). The value of $\chi^{2}$ divided by the degrees of freedom $\left(x^{2} / \mathrm{df}\right)$ has a low sensitivity to sample size and may be used as an index of goodness of fit (cut-off values: < $2-5$ ). Values of RMSEA of 0.08 or less indicate a good-fitting model, while TLI 
and CFI values greater than 0.90 indicate excellent model fit [53]. Cronbach's alpha values ensured internal reliability of the scales.

The normality of distribution of the restrained eating score was confirmed via a calculation of the skewness and kurtosis; values for asymmetry and kurtosis between -2 and +2 are considered acceptable in order to prove normal distribution [53]. These conditions consolidate the assumptions of normality in samples larger than 300 [54]. The Student $t$ and ANOVA tests were used to compare two and three or more means respectively. Pearson correlation was used to correlate two continuous variables. A multiple stage set of linear regressions was conducted, taking the restrained eating score as the dependent variable and all variables that showed a $p<0.05$ in the bivariate analysis as independent variables. Sociodemographic characteristics were entered at the first step; as a second step, practices followed by the participants (vomiting/starving/medications to lose weight, etc.) were entered as independent variables; at the third step, anxiety, depression, stress and body dissatisfaction were entered in the model; finally, the interaction BMI by body dissatisfaction was entered as an independent variable. $P<0.05$ was considered significant.

\section{Results}

\section{Confirmatory factor analysis}

The CFA results confirmed the one-factor structure of the restrained eating scale as follows: $\mathrm{X} 2 / \mathrm{df}=159.88 / 35=$ 4.57, $\mathrm{CFI}=0.96, \mathrm{TLI}=0.95, \mathrm{RMSEA}=0.08$ [0.068-0.093]

The standardized loading factors are summarized in Table 2.

\section{Bivariate analysis}

Higher anxiety, depression, stress, body dissatisfaction, higher physical activity index and BMI were significantly associated with more restrained eating (Table 3). Female gender, following a diet to lose weight, those who weigh

Table 2 Standardized coefficients and standard errors of the Dutch Restrained Eating Scale

\begin{tabular}{lccc}
\hline & Standard errors & Standard errors & $P$ \\
\hline Item 1 & 0.72 & - & - \\
Item 2 & 0.64 & 0.06 & $<0.001$ \\
Item 3 & 0.75 & 0.06 & $<0.001$ \\
Item 4 & 0.51 & 0.06 & $<0.001$ \\
Item 5 & 0.65 & 0.06 & $<0.001$ \\
Item 6 & 0.77 & 0.06 & $<0.001$ \\
Item 7 & 0.85 & 0.06 & $<0.001$ \\
Item 8 & 0.85 & 0.06 & $<0.001$ \\
Item 9 & 0.80 & 0.06 & $<0.001$ \\
Item 10 & 0.77 & 0.06 & $<0.001$ \\
\hline
\end{tabular}

themselves daily those who starve themselves to lose weight, and those who feel pressured by media to lose weight had significantly more restrained eating (Table 4).

Restrained eating score was calculated from the Dutch Restrained Eating Scale; numbers displayed in the table represent correlation coefficients obtained from the Pearson correlation test.

\section{Multivariable analysis}

The results of the hierarchical linear regressions are shown in Table 5 . In the final model that included all independent variables, female gender $(B=0.19)$, higher BMI $(B=0.49)$, higher physical activity index $(B=0.17)$, following a diet to lose weight $(B=0.26)$, starving oneself to lose weight $(B=0.13)$, more body dissatisfaction $(B=$ 1.09), higher stress $(B=0.18)$ were significantly associated with more restrained eating, whereas taking medications to lose weight $(B=-0.10)$ was significantly associated with less restrained eating (Table 5, Model 4). The interaction BMI by body dissatisfaction was significantly associated with restrained eating; in the group with low BMI, high body dissatisfaction was significantly associated with more restrained eating (Fig. 2).

\section{Discussion \\ Scale validation}

In our study, the DRES converged over a solution of one factor similarly to the study conducted among Lebanese adults [29] and Maltese female adults [27]. The Cronbach's alpha in our study is 0.924 , reflecting an excellent internal consistency. We observed equivalent results by Van Strien et al. in the original DRES with alpha between 0.8 and 0.95 [29]. Also Cronbach's alpha was 0.87 in the Maltese version [27] and 0.9 in the Spanish version [28]. However, the RMSEA value obtained in the confirmatory factor analysis is borderline and might not show adequate fit indices. Thus, the Arabic version of the Dutch Restrained Eating Scale is similar to the original version and might be considered a reliable tool for Lebanese adolescents. Future studies are needed for the assessment of additional psychometric properties of the Arabic version.

\section{Correlates of restrained eating}

To our knowledge, this is the first study done in Lebanon assessing factors associated with restrained eating in adolescents. Results showed that female gender, having a higher BMI, practicing more physical activity, following a diet to lose weight, starving oneself, higher body dissatisfaction and stress, were associated with more restrained eating. Taking medications to lose weight was associated with less restrained eating. The 
Table 3 Bivariate analysis of continuous variables associated with the restrained eating score

\begin{tabular}{ll}
\hline Variable & Correlation coefficient \\
\hline Body dissatisfaction & $r=0.365 ; p<0.001$ \\
Self-esteem & $r=-0.038 ; p=0.376$ \\
Anxiety & $r=0.187 ; p<0.001$ \\
Depression & $r=0.183 ; p<0.001$ \\
Stress & $r=0.218 ; p<0.001$ \\
Age & $r=-0.02 ; p=0.640$ \\
House crowding index & $r=-0.057 ; p=0.181$ \\
Body Mass Index & $r=0.245 ; p<0.001$ \\
Physical activity index & $r=0.168 ; p<0.001$ \\
\hline
\end{tabular}

interaction BMI by body dissatisfaction turned out to be significantly associated with restrained eating. Gender.

This study results showed that female gender was significantly associated with more restrained eating, in line with previous studies $[11,55]$. This might be due to the social pressure exerted on females, and the expectation of an ideal body, which leads girls to restrain from eating [11]. Moreover, with older age, a higher rate of body dissatisfaction was observed in females compared to their male counterparts [11]. While girls have more plans to decrease their weight, boys focus more on increasing weight and muscle building [11]. Girls might be more concerned with comparing their bodies to the ideal ones shown in media [11]. They seek the stereotype of beautiful thin women in order to confirm that they meet social expectation of femininity, consequently leading them to more restrained eating [11].

\section{Body Mass Index}

In our study, a significant positive relationship between BMI and restrained eating was established, in line with previous findings [10]. The higher the BMI of an adolescent, the higher the risk of dieting [10]. The mechanism by which BMI leads to restrained eating is not fully explained [10]. When individuals reach puberty, weight gain happens due to hormonal changes; individuals will thrive to become thinner and will go on a diet.

\section{Body dissatisfaction}

Our results showed a positive association between body dissatisfaction and restrained eating, in line with previous studies $[8,18,19]$. This could be explained by the fact that adolescents who have a high BMI are ashamed of their bodies, developing a negative image about themselves, resulting in restrained eating in order to decrease their weight [18].

In addition, our results showed that the interaction BMI by body dissatisfaction was significantly associated with restrained eating; in the group with low
Table 4 Bivariate analysis of categorical variables associated with the restrained eating score

\begin{tabular}{ll}
\hline Variable & Mean restrained eating score \\
\hline Gender & \\
Male & $22.09 \pm 8.71$ \\
Female & $27.65 \pm 9.18$ \\
$P$ & $\mathbf{0 . 0 0 1}$ \\
Following a diet to lose weight & \\
No & $23.13 \pm 7.98$ \\
Yes & $31.40 \pm 9.20$ \\
$P$ & $<\mathbf{0 . 0 0 1}$ \\
Vomiting to lose weight & \\
No & $25.96 \pm 9.06$ \\
Yes & $28.68 \pm 11.15$ \\
$P$ & 0.056
\end{tabular}

Taking medications to lose weight
No

Yes

$P$

Starving to lose weight

No

Yes

$P$

Weighing yourself daily

No

Yes

$P$

Family history of eating disorders

No

Yes

P

Pressured by media to lose weight

No

Yes

P
$26.40 \pm 9.23$

$25.27 \pm 10.73$

0.412

$24.79 \pm 8.68$

$31.04 \pm 9.91$

$<0.001$

$25.40 \pm 8.82$

$28.86 \pm 10.39$

$<0.001$

$25.63 \pm 9.39$

$28.14 \pm 9.11$

0.005

$24.58 \pm 9.36$

$29.40 \pm 8.59$

$<0.001$
BMI, high body dissatisfaction was significantly associated with more restrained eating. To our knowledge, in adults, higher weight suppression (WS), defined as the difference between maximal and current weight, is associated with decreased leptin and loss of control eating [56] and more body dissatisfaction [57]. The social stigma associated with obesity may cause shame, guilt and body dissatisfaction [58]. This is clinically important since body dissatisfaction is an unpleasant result of obesity, which serves as a motivation to follow unhealthy eating behaviors and weight control practices [59]. 
Table 5 Multivariable analysis: Linear regression taking the restrained eating score as the dependent variable

\begin{tabular}{|c|c|c|c|c|}
\hline Variable & Unstandardized Beta & Standardized Beta & $p$ & $95 \% \mathrm{Cl}$ \\
\hline \multicolumn{5}{|c|}{ Model 1: sociodemographic variables as independent variables. } \\
\hline Gender (females vs. males*) & 7.02 & 0.32 & $<0.001$ & $4.36-8.68$ \\
\hline Body Mass Index & 0.69 & 0.29 & $<0.001$ & $0.51-0.87$ \\
\hline Family history of eating disorders (yes vs. no*) & 1.43 & 0.07 & 0.083 & $-0.19-3.05$ \\
\hline Physical activity index & 0.08 & 0.23 & $<0.001$ & $0.05-0.10$ \\
\hline \multicolumn{5}{|l|}{ Nagelkerke $R^{2}=20.2 \%$} \\
\hline \multicolumn{5}{|c|}{ Model 2: sociodemographic variables and practices followed as independent variables. } \\
\hline Gender (females vs. males*) & 5.25 & 0.24 & $<0.001$ & $3.66-6.85$ \\
\hline Body Mass Index & 0.49 & 0.21 & $<0.001$ & $0.32-0.67$ \\
\hline Family history of eating disorders (yes vs. no*) & 0.74 & 0.04 & 0.353 & $0.83-2.32$ \\
\hline Physical activity index & 0.06 & 0.18 & $<0.001$ & $0.04-0.08$ \\
\hline Following a diet to lose weight (yes vs. no*) & 5.06 & 0.30 & $<0.001$ & $4.22-7.23$ \\
\hline Medication intake to lose weight (yes vs. no*) & -5.06 & -0.10 & 0.004 & $-5.71--1.05$ \\
\hline Starving oneself to lose weight (yes vs. no*) & 2.95 & 0.13 & 0.001 & $1.06-4.44$ \\
\hline Pressured by media to lose weight (yes vs. no*) & 0.36 & 0.04 & 0.370 & $-0.80-2.15$ \\
\hline Weighing yourself daily (yes vs. no*) & 2.04 & 0.10 & 0.016 & $-0.39-3.68$ \\
\hline
\end{tabular}

Nagelkerke $R^{2}=32.4 \%$

Model 3: sociodemographic variables, practices followed, mental health variables and body dissatisfaction and self-esteem as independent variables.

\begin{tabular}{|c|c|c|c|c|}
\hline Gender (females vs. males*) & 4.82 & 0.22 & $<0.001$ & $3.23-6.41$ \\
\hline Body Mass Index & 0.36 & 0.16 & $<0.001$ & $0.18-0.55$ \\
\hline Family history of eating disorders (yes vs. no*) & -0.001 & 0.001 & 0.999 & $-1.55-1.55$ \\
\hline Physical activity index & 0.06 & 0.17 & $<0.001$ & $0.03-0.08$ \\
\hline Following a diet to lose weight (yes vs. no*) & 4.57 & 0.24 & $<0.001$ & $3.01-6.13$ \\
\hline Medication intake to lose weight (yes vs. no*) & -4.60 & -0.14 & $<0.001$ & $-7.06--2.14$ \\
\hline Starving oneself to lose weight (yes vs. no*) & 3.00 & 0.14 & 0.001 & $1.26-4.73$ \\
\hline Pressured by media to lose weight (yes vs. no*) & -0.49 & -0.03 & 0.532 & $-2.05-1.06$ \\
\hline Body dissatisfaction & 1.77 & 0.08 & 0.031 & $0.17-3.37$ \\
\hline Self-esteem & 0.26 & 0.18 & $<0.001$ & $0.14-0.39$ \\
\hline Anxiety & 0.04 & 0.05 & 0.324 & $-0.04-0.12$ \\
\hline Depression & -0.15 & -0.09 & 0.124 & $-0.33-0.04$ \\
\hline ress & 0.33 & 0.20 & $<0.001$ & $0.16-0.50$ \\
\hline
\end{tabular}

Nagelkerke $R^{2}=37.4 \%$

Model 4: sociodemographic variables, practices followed, mental health variables and body dissatisfaction, self-esteem and the interaction of body dissatisfaction with BMI as independent variables.

$\begin{array}{lll}\text { Gender (females vs. males*) } & 4.93 & 0.23 \\ \text { Body Mass Index } & 1.14 & 0.49 \\ \text { Family history of eating disorders (yes vs. no*) } & -0.01 & 0.001 \\ \text { Physical activity index } & 0.05 & 0.16 \\ \text { Following a diet to lose weight (yes vs. no*) } & 4.50 & 0.23 \\ \text { Medication intake to lose weight (yes vs. no*) } & -4.73 & -0.15 \\ \text { Starving oneself to lose weight (yes vs. no*) } & 3.04 & 0.14 \\ \text { Pressured by media to lose weight (yes vs. no*) } & -0.42 & -0.02 \\ \text { Weighing yourself daily (yes vs no*) } & 1.59 & 0.08\end{array}$

\begin{tabular}{|c|c|}
\hline$<0.001$ & $3.36-6.50$ \\
\hline$<0.001$ & $0.71-1.57$ \\
\hline 0.989 & $-1.52-1.54$ \\
\hline$<0.001$ & $0.03-0.08$ \\
\hline$<0.001$ & $2.95-6.04$ \\
\hline$<0.001$ & $-7.16--2.30$ \\
\hline 0.001 & $1.32-4.76$ \\
\hline 0.591 & $-1.95-1.12$ \\
\hline 0.049 & $0.01-3.18$ \\
\hline
\end{tabular}


Table 5 Multivariable analysis: Linear regression taking the restrained eating score as the dependent variable (Continued)

\begin{tabular}{|c|c|c|c|c|}
\hline Variable & Unstandardized Beta & Standardized Beta & $p$ & $95 \% \mathrm{Cl}$ \\
\hline Body dissatisfaction & 1.43 & 0.98 & $<0.001$ & $0.83-2.03$ \\
\hline Self-esteem & 0.21 & 0.12 & 0.002 & $0.07-0.34$ \\
\hline Anxiety & 0.04 & 0.04 & 0.340 & $-0.04-0.12$ \\
\hline Depression & -0.13 & -0.07 & 0.179 & $-0.31-0.06$ \\
\hline Stress & 0.31 & 0.19 & $<0.001$ & $0.15-0.48$ \\
\hline Interaction BMI by body dissatisfaction & -0.05 & -0.99 & $<0.001$ & $-0.08--0.03$ \\
\hline Nagelkerke $R^{2}=39.1 \%$ & & & & \\
\hline
\end{tabular}

\section{Physical activity}

Our results showed that higher physical activity was related to more restrained eating, in line with a previous study that showed that exercise was able to favorably modify the short-term appetite control [60]. It is important to note that physical activity does not always imply going to a gym. During the COVID-19 pandemic, it is more frequent that adolescents exercise outdoor, or at home, with online/internet videos. The association between restrained eating and physical activity in determining energy intake after exercise, remains unclear and may be related to disinhibition (loss of restraint) levels [61]. Restrained eaters tend to decrease their energy intake after exercise, which creates a negative energy balance; the opposite is true about unrestrained eaters who actually increase their energy intake after physical activity [62]. More studies are recommended to solve the mystery of this dilemma.

\section{Following a diet}

Our study showed a positive association between following a diet and restrained eating, in line with previous findings [63]. People who follow a diet learn how to do self-control and have previous success in this regard, which makes them successful restrained eaters [64].

\section{Starving oneself}

Our study demonstrated a positive significant association between starving one self and restrained eating. In

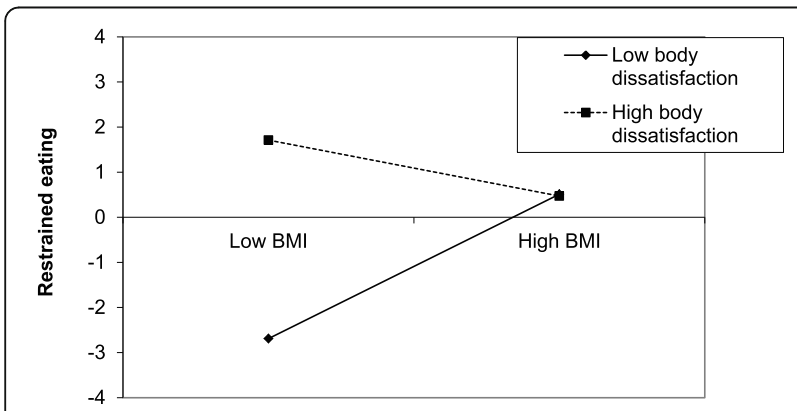

Fig. 2 Association between the interaction of body mass index with body dissatisfaction on restrained eating the general population, starving oneself does not precede restrained eating. In fact, previous findings $[65,66]$ showed that starving oneself and eating restriction are two behaviors that occur at the same time in order to lose weight. Controversially, another study demonstrated that dieting and restrained eating increase starvation and food cravings [67]. Therefore, our results should be interpreted with caution.

\section{Stress}

In our study, a positive relationship was established between stress and restrained eating. Literature is controversial in this regard; while previous studies showed that overeating can be used as a compensation of stress and negative mood $[68,69]$, other findings showed that stress can result in undereating [70]. More studies are needed to clarify this association.

\section{Medication to lose weight}

Our study showed a negative association between restrained eating and the use of medication to lose weight. No previous studies regarding this association have been conducted in adolescents. We hypothesize that this negative association could be due to the fact that when adolescents take medications to lose weight, they rely on them and do not restrict their eating because they think that medications alone are more than enough to control their weight [71]. At the same time, not restricted eating does not imply overeating. Those results should also be interpreted with caution.

\section{Limitations}

This study is a cross-sectional study, therefore we cannot conclude causality. It is important to point out that the confirmatory factor analysis results did not show adequate fit indices. Diagnosis was made by means of a questionnaire (less accurate) rather than a clinical interview. Females outnumbered males; furthermore, the majority of adolescents recruited went to school, and were from Mount Lebanon. The recruitment strategy (snowball technique) does not guarantee representativeness and extrapolation of our results to the general 
population. The questions used in the chosen scales addressed females more than males (questions referring to part of the body from the waist and downwards). Some scales (self-esteem and body dissatisfaction) have not been validated in Lebanon so far. A residual confounding bias is also possible since not all factors associated with restrained eating were considered in this study. Finally, we did not add another scale assessing restrained eating to help estimate the construct validity of the DRES in Lebanon. Future studies taking all these limitations into consideration are needed.

\section{Conclusions}

In conclusion, our study presents preliminary results for the validation of the Dutch restrained eating scale among Lebanese adolescents and revealed factors associated with restrained eating in this group. This study, by validating the DERS in Lebanese adolescents, would help clinicians detect harmful eating practices (restrained eating) in persons within this age group. The results of this study might serve as a first step towards the development of prevention strategies targeted towards promoting a healthy lifestyle in Lebanese adolescents.

\section{Abbreviations}

BMl: Body mass index; El: Eating Inventory; RRS: Revised Restraint Scale; DEBQ: Dutch Eating Behavior Questionnaire; DERS: Dutch Restrained Eating Scale; RE: Restrained eating; BDS: Beirut Distress Scale; HAM-A: Hamilton Anxiety Rating Scale; PHQ-9: Patient Health Questionnaire; FA: Factor analysis; CFA: Confirmatory factor analysis; KMO: Kaiser-Meyer-Olkin; RMSEA: Root Mean Square Error of Approximation; GFI: Goodness of Fit Index; AGFI: Adjusted Goodness of Fit Index

\section{Acknowledgements}

The authors acknowledge all participants who helped them in this study and Dr. Mariam Mhanna, Dr Reine Azzi and Dr Serena Samaha for their help in the data collection.

\section{Authors' contributions}

AM was responsible for the data collection and entry. MS, SH and SO designed the study; AM drafted the manuscript; $\mathrm{SH}$ carried out the analysis and interpreted the results; all authors reviewed the final manuscript and gave their consent.

\section{Funding}

None.

\section{Availability of data and materials}

All data generated or analyzed during this study are not publicly available to maintain the privacy of the individuals' identities. The dataset supporting the conclusions is available upon request to the corresponding author.

\section{Declarations}

\section{Ethics approval and consent to participate}

The Ethics and Research Committee of the Psychiatric Hospital of the Cross approved this study protocol (HPC-035-2020). Informed written consent was obtained from the students and their parents/guardians. All procedures performed in studies involving human participants were in accordance with the ethical standards of the institutional and/or national research committee and with the 1964 Helsinki Declaration and its later amendments or comparable ethical standards.
Consent for publication

Not applicable.

\section{Competing interests}

The authors have nothing to disclose.

\section{Author details}

${ }^{1}$ Faculty of Medicine and Medical Sciences, Holy Spirit University of Kaslik (USEK), Jounieh, Lebanon. ${ }^{2}$ INSPECT-LB: National Institute of Public Health, Clinical Epidemiology and Toxicology, Beirut, Lebanon. ${ }^{3}$ Faculty of Arts and Sciences, Holy Spirit University of Kaslik (USEK), Jounieh, Lebanon. ${ }^{4}$ Research and Psychology Departments, Psychiatric Hospital of the Cross, Jal Eddib, Lebanon.

Received: 26 January 2021 Accepted: 19 May 2021

Published online: 01 June 2021

\section{References}

1. Eating disorders.(n.d.).Retrieved from mayoclinic: https://www.mayoclinic. org/diseases-conditions/eating-disorders/symptoms-causes/syc-20353603.

2. Golden NH: Eating disorders in adolescence and their sequelae.Best Pract Res Clin Obstet Gynaecol 2003, 17(1):57-73.

3. Herpertz-Dahlmann B: Adolescent eating disorders: update on definitions, symptomatology, epidemiology, and comorbidity.Child Adolesc Psychiatr Clin N Am 2015, 24(1):177-196.

4. Qian J, Hu Q, Wan Y, Li T, Wu M, Ren Z, Yu D: Prevalence of eating disorders in the general population: a systematic review.Shanghai Arch Psychiatry 2013, 25(4):212-223.

5. Meule A: Cultural Reflections on Restrained Eating.Front Psychol 2016, 7:205.

6. Angle S, Engblom J, Eriksson T, Kautiainen S, Saha MT, Lindfors P, Lehtinen M, Rimpela A: Three factor eating questionnaire-R18 as a measure of cognitive restraint, uncontrolled eating and emotional eating in a sample of young Finnish females.Int J Behav Nutr Phys Act 2009, 6:41.

7. van Strien T, Ouwens MA: Counterregulation in female obese emotional eaters: Schachter, Goldman, and Gordon's (1968) test of psychosomatic theory revisited.Eat Behav 2003, 3(4):329-340.

8. Polivy J, Herman CP: Distress and eating: why do dieters overeat? Int J Eat Disord 1999, 26(2):153-164

9. Westenhoefer J, Broeckmann P, Munch AK, Pudel V: Cognitive control of eating behaviour and the disinhibition effect.Appetite 1994, 23(1):27-41.

10. Snoek HM, van Strien T, Janssens JM, Engels RC: Restrained eating and BMI: a longitudinal study among adolescents. Health Psychol 2008, 27(6):753-759.

11. Bex J: An examination of the relationship between attachment style and body image in adolescent girls: A focus on the mother-daughter relationship.2014.

12. Lin YW, Lin CY, Strong C, Liu CH, Hsieh YP, Lin YC, Tsai MC: Psychological correlates of eating behavior in overweight/obese adolescents in Taiwan: Psychometric and correlation analysis of the Three-Factor Eating Questionnaire (TFEQ)-R21.Pediatr Neonatol 2021, 62(1):41-48.

13. Quiles Marcos Y, Quiles Sebastian MJ, Pamies Aubalat L, Botella Ausina J, Treasure J: Peer and family influence in eating disorders: a meta-analysis.Eur Psychiatry 2013, 28(4):199-206.

14. Dakanalis A, Carra G, Calogero R, Fida R, Clerici M, Zanetti MA, Riva G: The developmental effects of media-ideal internalization and self-objectification processes on adolescents' negative body-feelings, dietary restraint, and binge eating .Eur Child Adolesc Psychiatry 2015, 24 (8):997-1010.

15. Barcaccia B, Balestrini $V$, Saliani AM, Baiocco R, Mancini F, Schneider BH: Dysfunctional eating behaviors, anxiety, and depression in Italian boys and girls: the role of mass media .Braz J Psychiatry 2018, 40 (1):72-77.

16. Chang FC, Lee CM, Chen PH, Chiu CH, Pan YC, Huang TF: Association of thin-ideal media exposure, body dissatisfaction and disordered eating behaviors among adolescents in Taiwan .Eat Behav 2013, 14 (3):382-385

17. Ata RN, Ludden AB, Lally MM: The effects of gender and family, friend, and media influences on eating behaviors and body image during adolescence .Journal of Youth and Adolescence 2007, 36 (8):1024-1037.

18. Brechan I, Kvalem IL: Relationship between body dissatisfaction and disordered eating: Mediating role of self-esteem and depression .Eating behaviors 2015, $17: 49-58$

19. Edman JL, Yates A, Aruguete MS, DeBord KA: Negative emotion and disordered eating among obese college students .Eat Behav 2005, 6 (4): 308-317. 
20. Gerner B, Wilson PH: The relationship between friendship factors and adolescent girls' body image concern, body dissatisfaction, and restrained eating .International Journal of eating disorders 2005, 37 (4):313-320.

21. Ricciardelli LA, McCabe MP: Self-esteem and negative affect as moderators of sociocultural influences on body dissatisfaction, strategies to decrease weight, and strategies to increase muscles among adolescent boys and girls Sex Roles 2001, 44 (3-4):189-207.

22. Slater A, Tiggemann M: Gender differences in adolescent sport participation, teasing, self-objectification and body image concerns .J Adolesc 2011, 34 (3):455-463.

23. Williamson DA, Martin CK, York-Crowe E, Anton SD, Redman LM, Han H, Ravussin E: Measurement of dietary restraint: validity tests of four questionnaires .Appetite 2007, 48 (2):183-192.

24. Van Strien T, Frijters JE, Bergers GP, Defares PB: The Dutch Eating Behavior Questionnaire (DEBQ) for assessment of restrained, emotional, and external eating behavior. International journal of eating disorders 1986, 5 (2):295-315

25. Forbush KT: Examining the structure of eating pathology through scale construction .2011.

26. Lluch A, Kahn J, Stricker-Krongrad A, Ziegler O, Drouin P, Méjean L: Internal validation of a French version of the Dutch Eating Behaviour Questionnaire European Psychiatry 1996, 11 (4):198-203.

27. Dutton E, Dovey TM: Validation of the Dutch Eating Behaviour Questionnaire (DEBQ) among Maltese women .Appetite 2016, 107 :9-14.

28. Cebolla A, Barrada JR, van Strien T, Oliver E, Banos R: Validation of the Dutch Eating Behavior Questionnaire (DEBQ) in a sample of Spanish women .Appetite 2014, 73 :58-64.

29. Saade S, Hallit S, Haddad C, Hallit R, Akel M, Honein K, Akiki M, Kheir N, Obeid S: Factors associated with restrained eating and validation of the Arabic version of the restrained eating scale among an adult representative sample of the Lebanese population: a cross-sectional study .J Eat Disord 2019, $7: 24$.

30. Pike KM, Hoek HW, Dunne PE: Cultural trends and eating disorders .Curr Opin Psychiatry 2014, 27 (6):436-442.

31. Story M, Neumark-Sztainer D, French S: Individual and environmental influences on adolescent eating behaviors .J Am Diet Assoc 2002, 102 (3 Suppl):S40-51.

32. Polivy J: Psychological consequences of food restriction .Journal of the American dietetic association 1996, 96 (6):589-592.

33. Comrey AL, Lee HB: A first course in factor analysis : Psychology press; 2013.

34. Melki IS, Beydoun HA, Khogali M, Tamim H, Yunis KA, National Collaborative Perinatal Neonatal N: Household crowding index: a correlate of socioeconomic status and inter-pregnancy spacing in an urban setting .J Epidemiol Community Health 2004, 58 (6):476-480.

35. Weary-Smith KA: Validation of the physical activity index (PAI) as a measure of total activity load and total kilocalorie expenditure during submaximal treadmill walking .University of Pittsburgh; 2007.

36. Van Strien T, Frijters JE, Van Staveren WA, Defares PB, Deurenberg P: The predictive validity of the Dutch restrained eating scale .International Journal of Eating Disorders 1986, 5 (4):747-755.

37. Garner DM: Eating disorder inventory-2 : psychological assessment resources Odessa, FL; 1991

38. Rosenberg M: Rosenberg self-esteem scale (RSE). Acceptance and commitment therapy Measures package 1965, 61 (52):18.

39. Malaeb D, Farchakh Y, Haddad C, Sacre H, Obeid S, Hallit S, Salameh P: Validation of the Beirut Distress Scale (BDS-10), a short version of BDS-22, to assess psychological distress among the Lebanese population .Perspect Psychiatr Care 2021.

40. Thompson E: Hamilton rating scale for anxiety (HAM-A) .Occupational Medicine 2015, 65 (7):601.

41. Hallit S, Haddad C, Hallit R, Akel M, Obeid S, Haddad G, Soufia M, Khansa W, Khoury R, Kheir N. Validation of the Hamilton anxiety rating scale and state trait anxiety inventory a and B in Arabic among the Lebanese population. Clin Epidemiol Global Health. 2020;8(4):1104-9.

42. Kroenke K, Spitzer RL, Williams JB: The PHQ-9: validity of a brief depression severity measure .Journal of general internal medicine 2001, 16 (9):606-613.

43. Sawaya H, Atoui M, Hamadeh A, Zeinoun P, Nahas Z: Adaptation and initial validation of the Patient Health Questionnaire - 9 (PHQ-9) and the Generalized Anxiety Disorder - 7 Questionnaire (GAD-7) in an Arabic speaking Lebanese psychiatric outpatient sample .Psychiatry Res 2016, 239 :245-252.

44. Blodgett Salafia EH, Jones ME, Haugen EC, Schaefer MK: Perceptions of the causes of eating disorders: a comparison of individuals with and without eating disorders .J Eat Disord 2015, $3: 32$.

45. Beaton DE, Bombardier C, Guillemin F, Ferraz MB: Guidelines for the process of cross-cultural adaptation of self-report measures.Spine 2000, 25 (24): 3186-3191.

46. Beaton D, Bombardier C, Guillemin F, Ferraz MB: Recommendations for the cross-cultural adaptation of health status measures. New York: American Academy of Orthopaedic Surgeons 2002:1-9.

47. Al-Bannay H, Jarus T, Jongbloed L, Yazigi M, Dean E: Culture as a variable in health research: perspectives and caveats. Health promotion international 2013, 29 (3):549-557.

48. Antunes B, Daveson B, Ramsenthaler C, Benalia H, Ferreira P, Bausewein C, Higginson I: The Palliative care Outcome Scale (POS) Manual for crosscultural adaptation and psychometric validation .London : Cicely Saunders Institute 2012.

49. Weidmer B: Issues and guidelines for translation in cross - cultural research In: Proceedings of the American Statistical Association, Section on Survey Research Methods: 1994 ; 1994

50. Maneesriwongul W, Dixon JK: Instrument translation process: a methods review .Journal of advanced nursing 2004, 48 (2):175-186.

51. Nejjari C, El Fakir S, Bendahhou K, El Rhazi K, Abda N, Zidouh A, Benider A, Errihani $H$, Bekkali R: Translation and validation of European organization for research and treatment of cancer quality of life Questionnaire-C30 into Moroccan version for cancer patients in Morocco .BMC research notes 2014, $7(1): 228$.

52. Marsh HW, Wen Z, Hau KT: Structural equation models of latent interactions: evaluation of alternative estimation strategies and indicator construction .Psychol Methods 2004, 9 (3):275-300.

53. George D: SPSS for windows step by step : A simple study guide and reference, 17.0 update, 10 / e : Pearson Education India; 2011.

54. Mishra P, Pandey CM, Singh U, Gupta A, Sahu C, Keshri A: Descriptive statistics and normality tests for statistical data .Ann Card Anaesth 2019, 22 (1):67-72.

55. Kiefer I, Rathmanner T, Kunze M: Eating and dieting differences in men and women Journal of Men's Health and Gender 2005, 2 (2):194-201.

56. Burnette CB, Simpson CC, Mazzeo SE: Relation of BMl and weight suppression to eating pathology in undergraduates .Eating behaviors 2018, $30: 16-21$.

57. Gorrell S, Reilly EE, Schaumberg K, Anderson LM, Donahue JM: Weight suppression and its relation to eating disorder and weight outcomes: a narrative review .Eat Disord 2019, 27 (1):52-81.

58. Müller R: Psychological consequences of obesity .Therapeutische Umschau Revue Therapeutique 2013, 70 (2):87-91.

59. Goldfield GS, Moore C, Henderson K, Buchholz A, Obeid N, Flament MF: Body dissatisfaction, dietary restraint, depression, and weight status in adolescents .Journal of school health 2010, 80 (4):186-192.

60. Martins C, Robertson MD, Morgan LM: Effects of exercise and restrained eating behaviour on appetite control .Proc Nutr Soc 2008, $67(1): 28-41$.

61. Lluch A, King NA, Blundell JE: Exercise in dietary restrained women: no effect on energy intake but change in hedonic ratings. Eur J Clin Nutr 1998, 52 (4):300-307.

62. Lluch A, King NA, Blundell JE: No energy compensation at the meal following exercise in dietary restrained and unrestrained women . Br J Nutr 2000, 84 (2):219-225.

63. Schaumberg K, Anderson D, Anderson L, Reilly E, Gorrell S: Dietary restraint: what's the harm? A review of the relationship between dietary restraint, weight trajectory and the development of eating pathology .Clinical Obesity 2016, 6 (2):89-100.

64. Van Koningsbruggen GM, Stroebe W, Aarts $\mathrm{H}$ : Successful restrained eating and trait impulsiveness .Appetite 2013, $60: 81-84$.

65. Song S, Zhang Y, Qiu J, Li X, Ma K, Chen S, Chen H: Brain structures associated with eating behaviors in normal-weight young females Neuropsychologia 2019, $133: 107171$.

66. Laessle RG, Tuschl RJ, Kotthaus BC, Pirke KM: Behavioral and biological correlates of dietary restraint in normal life .Appetite 1989, 12 (2):83-94.

67. Hill AJ: The psychology of food craving .Proc Nutr Soc 2007, 66 (2):277-285. 
68. Hou F, Xu S, Zhao Y, Lu Q, Zhang S, Zu P, Sun Y, Su P, Tao F: Effects of emotional symptoms and life stress on eating behaviors among adolescents .Appetite 2013, 68 :63-68.

69. Yau YH, Potenza MN: Stress and eating behaviors .Minerva endocrinologica 2013, 38 (3):255.

70. Reichenberger J, Kuppens $\mathrm{P}$, Liedlgruber $\mathrm{M}$, Wilhelm FH, Tiefengrabner $\mathrm{M}$, Ginzinger S, Blechert J: No haste, more taste: An EMA study of the effects of stress, negative and positive emotions on eating behavior .Biol Psychol 2018, $131: 54-62$.

71. Leung AW, Chan RS, Sea MM, Woo J: An overview of factors associated with adherence to lifestyle modification programs for weight management in adults .International Journal of Environmental Research and Public Health 2017, 14 (8):922

\section{Publisher's Note}

Springer Nature remains neutral with regard to jurisdictional claims in published maps and institutional affiliations.

Ready to submit your research? Choose BMC and benefit from:

- fast, convenient online submission

- thorough peer review by experienced researchers in your field

- rapid publication on acceptance

- support for research data, including large and complex data types

- gold Open Access which fosters wider collaboration and increased citations

- maximum visibility for your research: over $100 \mathrm{M}$ website views per year

At BMC, research is always in progress.

Learn more biomedcentral.com/submissions 